\title{
PENGARUH MODEL PELAJARAN TGT DAN TAI TERHADAP HASIL BELAJAR MAHASISWA PGSD UNIPA SURABAYA PADA POKOK BAHASAN KONSEP PENDIDIKAN IPS
}

\author{
Danang Prastyo \\ Program Studi Pendidikan Guru Sekolah Dasar \\ Universitas PGRI Adi Buana Surabaya \\ danangpgsd@gmail.com
}

\begin{abstract}
This research aims at knowing the influence of learning models Team Assisted Individualization (TAI) and Team Games Tournament (TGT) toward learning achievement of the students of Elementary Teacher Education (PGSD) Unipa Surabaya on the topics such as concept of social science education. The population of this research is the students of Elementary Teacher Education (PGSD) Unipa Surabaya year 2016. The sample of this research is the students of A class, B class and C class year 2014. This research uses experimental. Design uses Randomized Control Group Pretest-Postest Design. At the same time, the data analysis technique used statistic program SPSS version 16. From the research data analysis it can be seen that is no difference between TAI and TGT model in Social Science lesson to PGSD Student Unipa Surabaya.
\end{abstract}

Keyword: Team Games Tournament (TGT), Team Assisted Individualization (TAI), Learning Achievement.

\section{PENDAHULUAN}

Berkembangnya model pembelajaran koperatif atau kolaboratif dewasa ini mewajibkan pendidik untuk dapat mengimplementasikannya. Beragamnya model pembelajaran koperatif yang berkembang membuat pendidik binggung untuk menerapkannya. Sebagai pendidik di perguruan tinggi, dosen harus dapat memilih model pembelajaran yang sesuai agar tujuan pembelajaran dapat tercapai.

Menurut Huda (2014:196) ada 10 model pembelajaran dalam pendekatan kolaboratif yaitu Team Games Tournament, Team Assisted Individualis, Student Team Achievement, NHT, Jigsaw,
TPS, TSTS, Role Playing, Pair Check dan Cooperative Script. Dari 10 pendekatan kolaboratif yang ada tidak semua pendekatan dapat digunakan dalam proses pembelajaran, karena harus disesuaikan dengan tujuan pembelajaran.

Sebagai mata kuliah, keberadaan Konsep Dasar IPS harus dapat dikuasi oleh mahasiswa PGSD Unipa Surabaya. Banyak konsep dan generalisasi yang dikuasai pada mata kuliah Konsep IPS dasar, sehingga dibutuhkan pemilihan model pembelajaran yang tepat. Dari beberapa hasil observasi ditemukan dosen pengampu mata kuliah Konsep IPS dasar masih menggukan metode 
ceramah, sehingga tujuan pembelajaran sulit tercapai.

Jika dinilai penggunaan metode ceramah belum memberikan banyak manfaat kepada mahasiswa hal ini dikarenakan pembelajaran berlangsung monoton, tidak menarik dan terlihat menggurui. Menurut Ratumanan (2004:43) dampak negatif apabila pendidik melakukan dominasi pada PBM, peserta didik akan takut untuk menyampaikan pendapatnya pada saat diskusi, karena takut disalahkan oleh pendidik dan teman-temannya. Peserta didik selalu dianggap sebagai orang yang tidak mengerti dan hanya menunggu pengetahuan dari guru. Akibatnya peserta didik menjadi pasif dan pendidik yang aktif.

Sementara itu Sanjaya (2007:257) menjelaskan, dampak dari pembelajaran yang didominasi pendidik yaitu menjadikan pengetahuan peserta didik cepat hilang dan terlupakan pada saat selesai pembelajaran. Selain itu Sulkifly (dalam Wonda, 2009: 4) mengatakan, pembelajaran IPS (Ilmu Pengetuhan Sosial) dengan menerapkan metode ceramah mengakibatkan materi pelajaran tidak berkembang, suasana belajar yang kaku, peran siswa dalam mengikuti pembelajaran di kelas sangat minim dan tidak mampu meningkatkan prestasi belajar

Dari masalah di atas peneliti tertantang menerapkan model pembelajaran TGT dan TAI ke dalam pemebelajaran. Peneliti menilai penerapan TGT dan TAI mampu meningkatkan hasil belajar daripada menggunakan metode ceramah pada pembelajaran mahasiswa di PGSD Unipa Surabaya. Dalam penerapannya TGT dinilai berhasil dalam meningkatkan skil-skil dasar, pencapaian hasil belajar, interaksi positif antar siswa, harga diri dan sikap penerimaan pada siswa lain yang berbeda (Huda, 2014: 197). Sedangkan TAI diangap berhasil karena mampu meningkatkan kemampuan, belajar berkelompok dan mampu memotivasi siswa selalu untuk belajar (Huda, 2014: 200).

Dari manfaat pembelajaran TGT dan TAI, peneliti ingin membuat penelitian Pengaruh Model Pelajaran TGT dan TAI Terhadap Hasil Belajar Mahasiswa PGSD Unipa Surabaya pada Pokok Bahasan Konsep Pendidikan IPS.

\section{METODE PENELITIAN}

\section{A. Rancangan Penelitian}

Dalam penelitian peneliti menggunakan penelitian eksperimen. Penelitian eksperimen dilakukan karena peneliti akan mengujicobakan ke tiga kelas, yaitu kelas dengan model pembelajaran TGT dan kelas dengan model pembelahjaran TAI dan kelas dengan model pembelajaran konvesional. 


\section{B. Pembuatan Perangkat Pembelajaran}

Sebelum penelitian diterapkan pada kelompok eksperimen, peneliti akan membuat beberapa perangkat pembelajaran TAI dan TGT yang akan diujikan pada kelompok uji coba. Untuk pembuatan perangkat pembelajaran TAI meliputi: Rencana Pembelajaran (RPP) dan Tes Hasil Belajar (THB).

\section{Waktu}

Untuk waktu pelaksanaan uji coba perangkat pembelajaran disesuaikan dengan pendidik yang mengajar bidang studi.

\section{Sampel Penelitian}

Uji coba dilaksanakan pada Jurusan PGSD Unipa tahun 2015 dengan memilih satu kelas secara acak dari empat kelas paralel yang berkemampuan setara. Untuk mengetahui kemampuan peserta didik agar setara peneliti meminta saran dari Kaprodi PGSD.

\section{E. Instrumen Penelitian Uji Coba}

Dalam mengumpulkan data uji coba, peneliti membuat instrumen THB dikembangkan sendiri oleh peneliti. Tes dalam penelitian ini berupa tes pilihan ganda. THB diberikan kepada peserta didik sebanyak dua kali yaitu sebelum dan sesudah dimulai pokok bahasan Konsep Pendidikan IPS.

\section{F. Uji Validitas dan Reliabilitas Perangkat Pembelajaran}

Untuk menguji agar THB valid peneliti menggunakan rumus Korelasi Person Biserial. Sedangkan untuk menguji agar tes THB reliabel dengan menggunakan rumus rumus KR-20.

\section{G. Rancangan Penelitian}

Peneltian ini menggunakan desain Randomized Control Group PretestPostest Desaing. Desain ini dinilai mendekati sempurna mengingat ada kelompok kontrol, ada perlakukan, subjek ditempatkan secara acak dan adanya pretest dan posttes untuk memastikan efektiviatas perlakuan yang diberikan (Maksum, 2009:49).

\section{Rancangan Eksperimen}

\begin{tabular}{|l|c|c|c|}
\hline Kelompok & Pretes & Perlakuan & Postest \\
\hline Eksperimen 1 & $\mathrm{T} 1$ & $\mathrm{X} 1$ & $\mathrm{~T} 2$ \\
Eksperimen 2 & $\mathrm{T} 1$ & $\mathrm{X} 2$ & $\mathrm{~T} 2$ \\
Kontrol & $\mathrm{T} 1$ & $\mathrm{X}$ & $\mathrm{T} 2$ \\
\hline
\end{tabular}

Keterangan :

X1 = Perlakuan metode 1

X2 = Perlakuan metode 2

$\mathrm{X}=$ Konvesional

T1 = Pretest kelompok Eksperimen 1,2 dan kelompok kontrol

T2 = Post-test kelompok Eksperimen 1,2 dan kelompok kontrol. 


\section{H. Teknik Analisis Data Eksperimen}

Penelitian ini menggunakan dua teknik analisis data, yaitu analisis statistik deskriptif dan analisis statistik inferensial. Untuk menetukan uji beda peneliti menggunakan Penghitungan ANOVA dilakukan dengan bantuan program SPSS versi 16.0 .

\section{HASIL DAN PEMBAHASAN}

Untuk mengukur apakah kelas A, kelas B dan kelas C pada angkatan 2014 mempunyai kemampuan yang sama, maka peneliti menggunakan uji homogenitas dan lineritas. Pada uji homogenitas dan lineritas terlihat bahwa kemampuan masing-masing kelas sama dan merata. Untuk memperjelas kemampuan ketiga kelas dapat dilihat pada tabel dibawah ini: pada tabel dan grafik di bawah ini:

Tabel 4.1

Descriptive Statistics

\begin{tabular}{|l|c|c|c|c|c|}
\hline & $\mathrm{N}$ & Minimum & Maximum & Mean & Std. Deviation \\
\hline Kelas A & 40 & 30.00 & 95.00 & 72.5500 & 10.95901 \\
Kelas B & 40 & 60.00 & 99.00 & 78.8000 & 9.54396 \\
Kelas C & 41 & 50.00 & 90.00 & 73.9474 & 10.60073 \\
Valid N & 38 & & & & \\
(listwise) & & & & & \\
\hline
\end{tabular}

Dari tabel deskriptif diatas dapat maksimum yang diperoleh kelas A disimpulkan bahwa jumlah mahasiswa sebesar 95 dan kelas B sebesar 99, pada kelas A sebanyak 40 orang dan sedangkan pada kelas C sebesar 90. Nilai kelas B sebanyak 40 orang. Sedangkan rata-rata pada kelas A sebesar 72.5500 pada kelas C berjumlah 41 orang. Nilai pada kelas B sebesar 72.56, dan pada minimum yang diperoleh kelas A kelas D sebesar 73.94. Besaran standar sebesar 30 dan kelas B sebesar 60, deviasi pada kelas A adalah 6.59662, sedangkan pada kelas C sebesar 50. Nilai kelas B 78.8000 dan kelas C 10.60073.

Tabel 4.2

Estimated Distribution Parameters

\begin{tabular}{|ll|r|r|r|}
\hline & & Kelas A & Kelas B & Kelas C \\
\hline $\begin{array}{l}\text { Normal } \\
\text { Distribution }\end{array}$ & Locat & 72.5500 & 78.8000 & 73.9474 \\
& ion & & & \\
& Scale & 10.95901 & 9.54396 & 10.60073 \\
\hline
\end{tabular}

The cases are unweighted. 
Dari data pada tabel estimasi parameter diribusi menunjukkan bahwa ketiga kelas tersebut berada dalam distribusi normal. Perinciannya sebagai berikut, nilai pada kelas A sebesar 72.5500 dalam skala 10.95901, untuk kelas B nilainya sebesar 78.8000 dalam skala 9.54396, dan kelas C nilainya sebesar 73.9474 dalam skala 10.60073. Sehingga kesimpulannya, ketiga kelas tersebut homogen, artinya siswa pada kelas A, kelas B dan kelas C memiliki kemampuan yang sama. Penjelasan homogenitas ini juga dapat dilihat pada grafik masing-masing kelas dibawah ini. Dalam tiap grafik tampak data mengumpul pada sekitar garis, tidak menyebar, sehingga datanya dapat dikatakan homogen.

\section{Grafik 4.1}

\section{Uji Normalitas Kelas A}

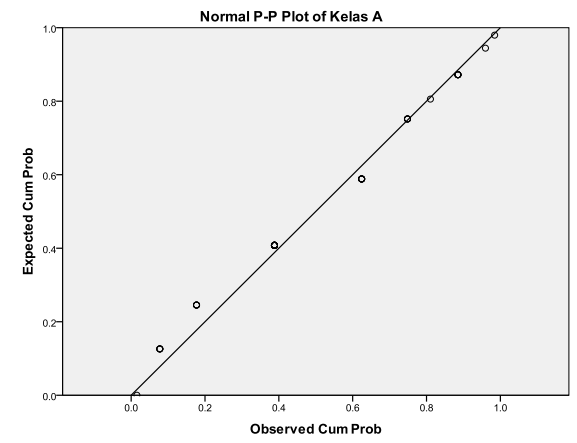

\section{Grafik 4.2}

\section{Uji Normalitas Kelas B}

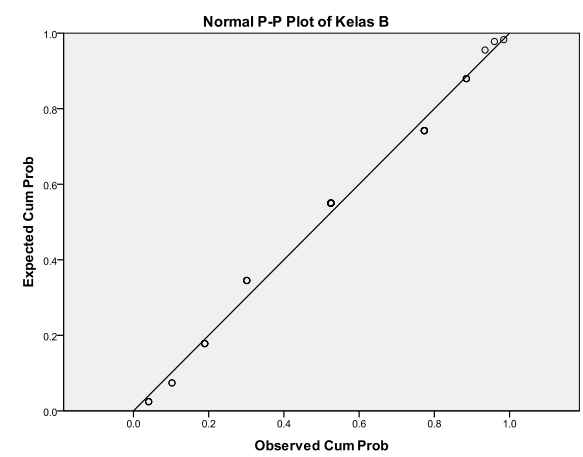

\section{Grafik 4.3}

Uji Normalitas Kelas C

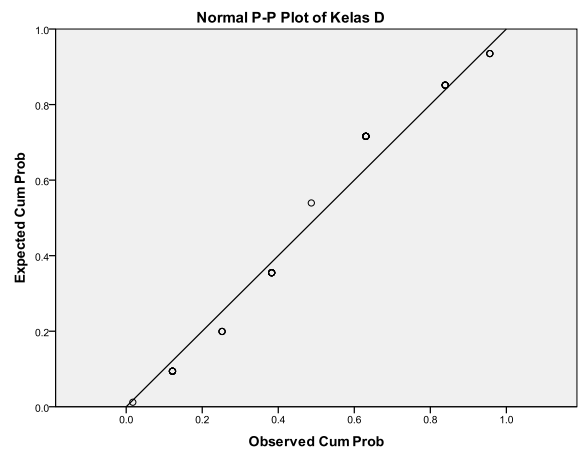

\section{A. Deskriptif Hasil Pembuatan} Perangkat Pembelajaran

Pada penelitian ini peneliti membuat beberapa perangkat pembelajaran TAI dan TGT, diantaranya adalah RPP, dan THB. Sebelum diujicobakan peneliti meminta masukan dan saran ke validator untuk melakukan validasi terhadap RPP dan THB. Untuk hasil validasi oleh validator akan dijelaskan sebagai berikut.

\section{Hasil Validasi Ahli}

Pada validasi para ahli difokuskan pada format, isi, ilustrasi, dan bahasa yang mencakup semua perangkat pembelajaran yang dikembangkan. Hasil validasi ahli berupa koreksi, kritik dan saran yang digunakan sebagai dasar untuk melakukan revisi dan penyempurnaan terhadap perangkat pembelajaran.

\section{a. Validator}

Validator yang melakukan validasi terhadap perangkat pembelajaran terdiri dari 2 orang yaitu 1 orang yang bergelar S-2 dari Jurusan 
Bahasa Indonesia dan 1 orang yang bergelar S-2 dari Jurusan PGSD.

perangkat pembelajaran, peneliti b. Hasil Validasi Ahli

Data penilaian ahli terhadap RPP mengacu pada saran-saran validator. Untuk hasil dari validator sebagai berikut:

dan THB didasarkan pada indikator

\section{c. Hasil Validasi RPP}

format, isi, dan bahasa yang tertuang

Berdasarkan penilaian para validator dalam instrument lembar validasi diperoleh saran yang digunakan peneliti perangkat pembelajaran. Penilaian dalam merevisi RPP. Untuk saran perangkat pembelajaran hanya dilakukan oleh dua validator dengan perbaikan beberapa kesalahan penulisan menuliskan tanda cek " $\sqrt{ }$ " pada kolom yang sesuai dengan skor nilai yang dapat dilihat pada lampiran. Dengan dan ejaan pada naskah telah diperbaiki sesuai dengan coretan validator sedangkan revisi yang lainnya dapat dilihat pada tabel berikut.

demikian dalam melakukan revisi

Tabel 4.3

Revisi RPP Berdasarkan Hasil Validasi

\begin{tabular}{|l|l|l|l|}
\hline No & Yang direvisi & \multicolumn{1}{|c|}{ Sebelum direvisi } & \multicolumn{1}{|c|}{ Sesudah direvisi } \\
\hline 1 & Waktu & $\begin{array}{l}2 \times \text { Pertemuan (3 } \times 45 \\
\text { menit) }\end{array}$ & $\begin{array}{l}2 \times \text { Pertemuan }(3 \times 55 \\
\text { menit }\end{array}$ \\
\hline 2 & $\begin{array}{l}\text { Sumber bahan } \\
\text { dan Pustaka pada } \\
\text { RPP }\end{array}$ & $\begin{array}{l}\text { Tidak dicantumkan dalam } \\
\text { RPP }\end{array}$ & $\begin{array}{l}\text { Dicantumkan Bahan dan } \\
\text { dan Pustaka dalam RPP }\end{array}$ \\
\hline 3 & $\begin{array}{l}\text { Indikator dalam } \\
\text { RPP }\end{array}$ & $\begin{array}{l}\text { Tidak menunjukkan } \\
\text { capaian yang jelas }\end{array}$ & $\begin{array}{l}\text { Capaian harus jelas dan } \\
\text { terukur }\end{array}$ \\
\hline
\end{tabular}

\section{d. Hasil Validasi THB}

Hasil validasi THB dari para validator pada umumnya menyimpulkan THB ini baik dan dapat digunakan dengan sedikit revisi. Untuk revisi THB dapat dilihat pada tabel di bawah ini:

Tabel 4.4

\section{Revisi THB Berdasarkan Hasil Validasi}

\begin{tabular}{|l|c|c|}
\hline No & Sebelum Revisi & Sesudah Revisi \\
\hline 1 & Tanpa menyertakan kunci jawaban & Telah menyertakan kunci jawaban \\
\hline
\end{tabular}

Dari beberapa penilaian di atas, secara umum hasil validasi para ahli terhadap perangkat pembelajaran yang telah dibuat adalah:
1) RPP mempunyai kategori baik dan dapat digunakan dengan sedikit revisi.

2) THB mempunyai kategori valid, dapat dipahami dengan sedikit revisi. 


\section{B. Uji Coba Perangkat Pembelajaran}

Uji coba dilakukan untuk menyempurnaan pembelajaran sebelum perangkat pembelajaran digunakan pada kelas eksperimen. Uji coba dilaksanakan 2 kali pertemuan, sesuai dengan rencana pembelajaran di kelas. Untuk pelasanaan uji coba perangkat pembelajaran dilakukan di kelas 2014 A.

\section{Hasil Pretest dan Posttest}

Dalam uji coba perangkat pembelajaran peneliti mengujicobakan Tes Hasil Belajar (THB) untuk menentukan soal-soal yang dianggap valid. Dari 30 soal yang diujikan yang valid hanya 18 soal dan soal yang valid akan digunakan peneliti untuk melakukan pretest dan posttest.

Tabel 4.5

Paired Samples Statistics

\begin{tabular}{|ll|r|r|r|r|}
\hline & & & & \multicolumn{2}{c|}{$\begin{array}{c}\text { Std. Error } \\
\text { Mean }\end{array}$} \\
\hline Pair 1 & Pretest TAI & 62.9216 & 37 & 15.04298 & 2.47305 \\
& Postest TAI & 70.1892 & 37 & 17.65029 & 2.90169 \\
Pair 2 & Pretest TGT & 59.8750 & 36 & 16.17775 & 2.69629 \\
& & & & & \\
& Postest TGT & 73.6667 & 36 & 14.04584 & 2.34097 \\
\hline
\end{tabular}

Dari data di atas menunjukkan bahwa dalam pelaksanaan pretes siswa kelas A diikuti oleh 37 orang, sedangkan pelaksanaan pretest siswa kelas siswa kelas $\mathrm{C}$ berjumlah 36 orang. Untuk hasil rata-rata pelaksanaan pretest kelas A sebesar 62.92 sedangkan pelaksanaan pretest kelas C sebesar 59.87. Sementara itu untuk pelaksanaan posttest kelas A, nilai rata-rata sebesar 70.18 , sedangkan untuk pelaksanaan posttest kelas $C$ nilai rata-rata sebesar 73.66 .

\section{Hubungan Pretes dan Postes}

Dari hasil pretest dan postest yang dilakukan dua kelas menunjukkan bahwa ada perbedaan hasil belajar dengan menggunakan model pembelajaran TAI dan TGT. Untuk hasilnya sebagai berikut.

Tabel 4.6

Paired Samples Test

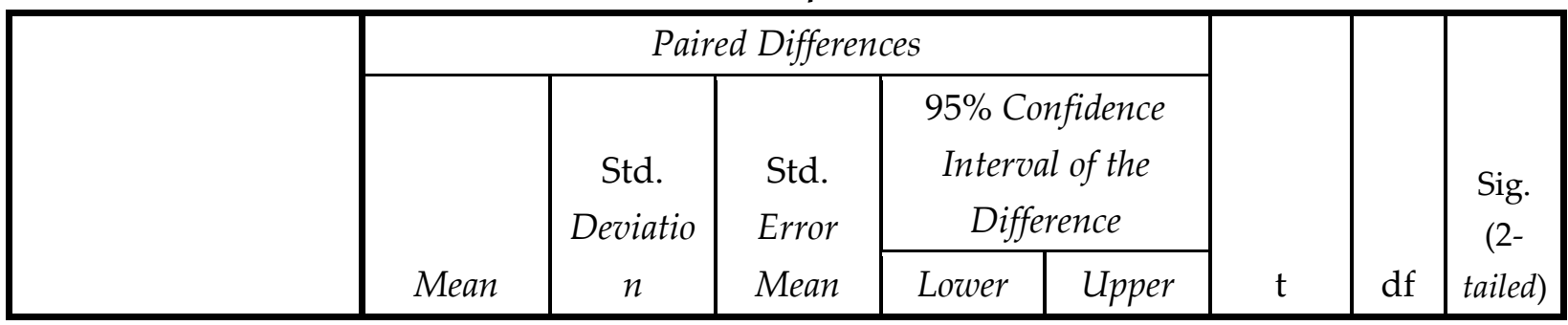




\begin{tabular}{|ll|r|r|r|r|r|r|r|r|}
\hline Pair 1 $\begin{array}{l}\text { Pretest TAI } \\
\text { - Postest } \\
\text { TAI }\end{array}$ & -7.26757 & 20.74398 & 3.41029 & -.35118 & -2.131 & 36 & .040 \\
Pair 2 $\begin{array}{l}\text { Pretest TGT } \\
\text { - Postest } \\
\text { TGT }\end{array}$ & -13.79167 & 17.06055 & 2.84343 & -14.18396 & -8.01921 & -4.850 & 35 & .000 \\
\end{tabular}

Dari tabel diatas, diperoleh kesimpulan bahwa ada perbedaan hasil belajar yang signifikan dengan metode pembelajaran TAI, signifikansi sebesar $0.040(<0.05)$. Begitu juga dengan hasil belajar yang signifikan dengan metode pembelajaran TGT, signifikansi sebesar $0.000(<0.05)$.

\section{Perbedaan Pretest dan Postest}

Tabel 4.7

Independent Samples Test

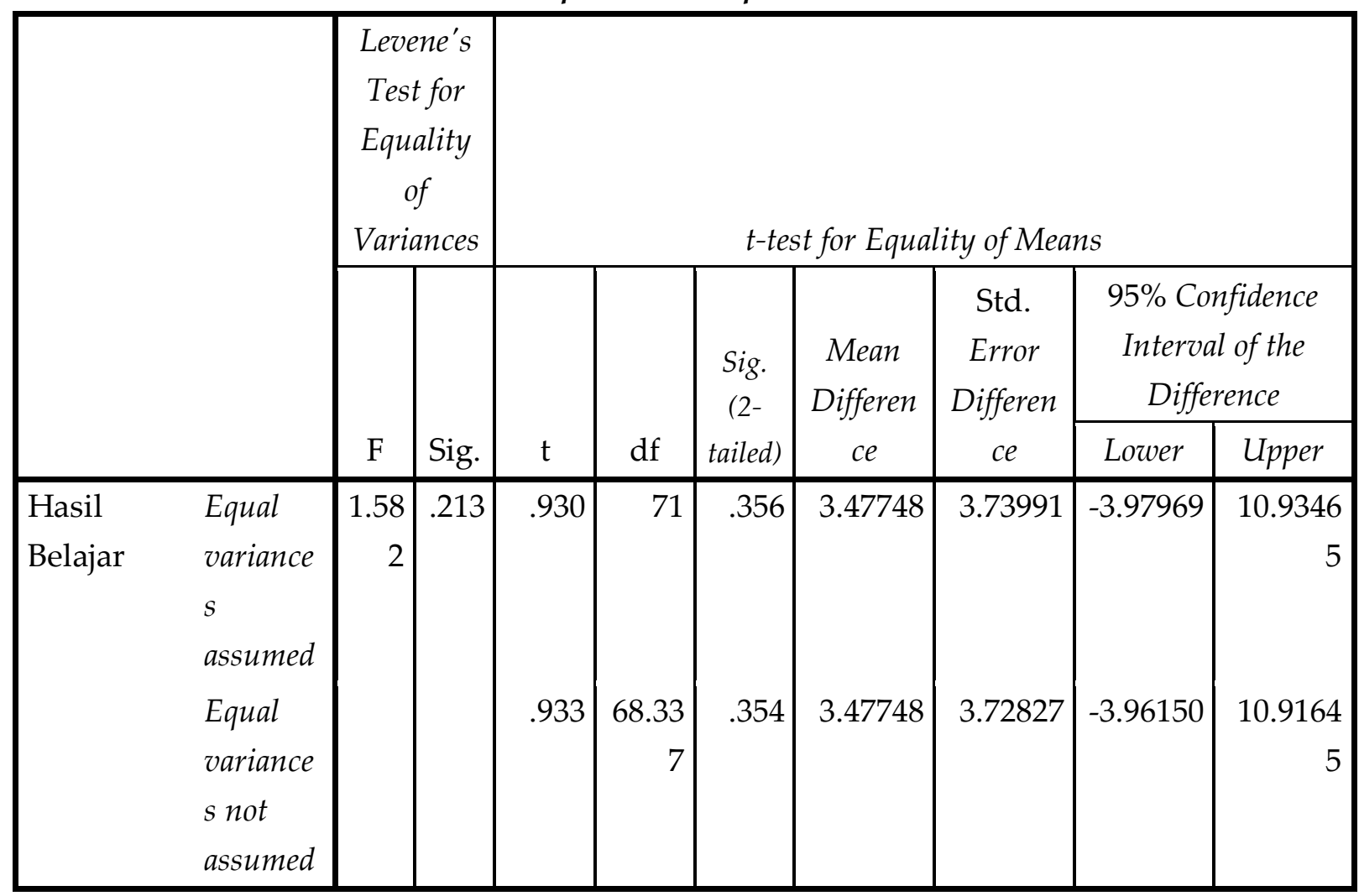

Dari data diatas dapat dijelaskan bahwa signifikansi sebesar 0.213 (>0.05) artinya tidak ada perbedaan hasil belajar pada penggunaan metode TAI dan TGT pada mahasiswa. Sehingga kesimpulannya, hipotesis nol diterima.

\section{SIMPULAN}

Dari penelitian di atas dapat disimpulkan, tidak ada perbedaan hasil belajar antara model pembelajaran TAI dengan TGT pada mata pelajaran Konsep Pendidikan IPS. 


\section{DAFTAR PUSTAKA}

Huda, Miftahul. 2004. Model-Model Pengajaran dan Pembelajaran.

Yogyakarta: Pustaka Pelajar.

Maksum, Ali. 2009.

Metodologi Penelitian dalam

Olahraga. Surabaya: Fakultas Ilmu

Keolahragaan Universitas

Negeri Surabaya.

Ratumanan, T.G. 2004. Belajar dan

Pembelajaran. Surabaya: Unesa

University Press.

Sanjaya, W. 2007. Kajian Kurikulum

Pembelajaran. Bandung: Sekolah Pascasarjana UPI.

Wonda, Hiwa. 2009. Penerapan Model Pemebelajaran Terpadu Tipe Connected dalam Pembelajaran IPS di SD. Makalah Komprehensif. Unesa. 